\title{
Retraction of the Article
}

Title of the Article: Correlations Among Depressive Symptoms, Personality, and Synthetic HouseTree-Person Drawings in South Korean Adults

\section{Author: Eun Jin Lee}

The editorial office of Psychologia acknowledges that the article "Correlations Among Depressive Symptoms, Personality, and Synthetic House-Tree-Person Drawings in South Korean Adults" by Eun Jin Lee, which was published in Psychologia 2018, Vol.61(3) pp. 200-209 has been retracted from the issue according to the request from the author for the reason that the publication year of the article was inappropriate. The article will be re-published in Vol.61(4).

The editorial office apologizes to the author for this inconvenience. 